\title{
METODOLOGIA DE CAMPOS E ARMAS DA COMPETIÇÃO APLICADA AO ESTUDO DA COMPETITIVIDADE DE CONCESSIONÁRIAS CHEVROLET ${ }^{1}$
}

\author{
COMPETITIVENESS OF CHEVROLET DEALERS: A STUDY EMPLOYING THE \\ FIELDS AND WEAPONS OF THE COMPETITION METHODOLOGY
}

\author{
Paula Meyer Soares Passanezi ${ }^{2}$ \\ José Celso Contador ${ }^{3}$
}

\begin{abstract}
Resumo: Este artigo apresenta uma metodologia para estudar a competitividade empresarial baseada no modelo de campos e armas da competição, mostra sua aplicação à compreensão e ampliação da competitividade do setor de venda de peças de concessionárias Chevrolet e relata os resultados da pesquisa de campo realizada. Essa nova metodologia, que serve para analisar, explicar e aumentar a competitividade de uma empresa por meio de variáveis quantitativas e qualitativas, separa a estratégia competitiva de negócio da estratégia operacional. A primeira é representada por alguns dos 17 campos da competição, e a segunda, pelas armas da competição. A análise da influência das estratégias é feita por meio de métodos estatísticos. Inúmeras conclusões foram extraídas, entre elas a confirmação das hipóteses, validadas segundo o método popperiano dedutivo de prova: 1) não é a estratégia de negócio que explica a competitividade empresarial, mas sim as operacionais; e 2) para ampliar sua competitividade, a empresa deve aumentar a intensidade das armas que são relevantes para os campos onde decidiu competir, o que é medido pela variável foco. Essas conclusões são coerentes com os resultados das várias pesquisas realizadas para validar o modelo de campos e armas da competição. A pesquisa é aplicada, explicativa, experimental e qualiquantitativa. Atestam a relevância e a contribuição científicas deste artigo, a apresentação de uma nova metodologia de estudo da competitividade empresarial e sua aplicação ao setor de venda de peças de concessionárias de veículos. A originalidade e o ineditismo do artigo são comprovados pelo fato de não ter sido encontrado na literatura estudo semelhante sobre competitividade de concessionárias de veículos automotores.
\end{abstract}

Palavras-chave: Estratégia; Competitividade; Campos e armas da competição; Indústria automobilística; Concessionárias automobilísticas.

Abstract: This article discusses the methodology and the results of field research carried out in the Spare Parts section of Chevrolet dealers. A new methodology that can be employed to analyze and explain the competitiveness of a group of companies, and can also increase the competitiveness of a company was adopted in the research. This methodology, based on the Fields and Weapons of the Competition model, analyzes the business competitive strategies and the operational strategies separately. The first set of strategies is represented by some of the 17 fields of competition, and the second, by the weapons of the competition. The methodology employs mathematical variables to explain business competitiveness. The analysis of the influence of the strategies is carried out statistically. Numerous conclusions were drawn, such as: 1) it is not the business strategy adopted that explains business competitiveness, but rather the operational strategies employed, and 2) to increase its competitiveness, the company must increase its focus on weapons that are relevant to the fields where it has decided to compete.

Keywords: Strategies; Competitiveness; Fields and weapons of the competition; Automobile industry; Automobile dealers.

\footnotetext{
${ }^{1}$ Artigo Recebido em 20.09.2009. Revisado por pares em 26.07.2011. Recomendado em 22.08.2011 por Leomar dos Santos Editor. Publicado em 21.09.2011.

Organização Responsável pelo periódico: Universidade regional de Blumenau - FURB - www.furb.br/rn
}

\footnotetext{
${ }^{2}$ Universidade Nove de Julho - UNINOVE - paula.passanezi@ hotmail.com

${ }^{3}$ Universidade Paulista - UNIP - celsocontador@terra.com.br
} 


\section{INTRODUÇÃO}

Os objetivos deste artigo são apresentar uma metodologia para estudar a competitividade empresarial baseada no modelo de campos e armas da competição, mostrar sua aplicação à compreensão e ampliação da competitividade do setor de venda de peças de concessionárias Chevrolet e relatar os resultados da pesquisa de campo realizada.

Quais razões levam uma concessionária Chevrolet a ser mais competitiva que outra no setor de venda de peças? Esse problema motivou a pesquisa aqui relatada, realizada num conjunto de 13 concessionárias com diferentes níveis de competitividade.

Desse problema, derivaram os objetivos da pesquisa: identificar as estratégias competitivas de negócio e as estratégias competitivas operacionais que explicam a competitividade do setor de venda de peças das concessionárias Chevrolet e recomendar medidas para aumentar o grau de competitividade delas.

Colocados o problema e os objetivos, surgiu a questão: Qual referencial teórico usar, já que o pensamento sobre estratégia empresarial evoluiu muito nos últimos quarenta anos?

As obras de Selznick (1957), Chandler (1962), Learned et al. (1965) e Ansoff (1966) deram origem ao que viria a ser genericamente chamado Planejamento Estratégico. $\mathrm{O}$ Planejamento Estratégico se notabilizou na década de 1970 principalmente pela distinção entre planejamento estratégico, tático e operacional, pela definição do negócio, visão e missão da empresa, pelo modelo SWOT (strengths, weaknesses, opportunities, threats) que analisa as forças e fraquezas versus oportunidades e ameaças, pela matriz BCG (Boston Consulting Group) e PIMS (Profit Impact of Market Strategies).

A década de 1980 foi distinguida pela estratégia competitiva e vantagem competitiva de Michael Porter, que teve perspicácia para perceber a importância do ambiente externo da empresa e do posicionamento dela nesse ambiente e apresentou em 1979 "as cinco forças competitivas que determinam da rentabilidade da indústria” (PORTER, 1979, 1980). Mais tarde, disseminou o conceito de vantagem competitiva (PORTER, 1985). Desde então, ele exerceu forte influência sobre o meio acadêmico e o empresarial.

A prevalência que Porter atribui aos fatores externos à empresa para explicar a competitividade empresarial fez surgir opositores nas décadas de 1980 e 1990, muitos dos quais se agregaram na RBV (Resource Based View, denominação crida por Wernerfelt, 1984), cuja ênfase está nos fatores internos da empresa - "empresa pode criar vantagens competitivas a partir de seus recursos, tornando-se mais lucrativa" (BARNEY, 1986a, 1986b, 1991, 2001; PETERAF, 1993; KROGH e ROSS, 1995). A RBV é um modelo de desempenho focado nos recursos e capacidades controlados pela empresa como fontes de vantagem competitiva que devem ser valiosos, raros, de difícil imitação e organizados.

A década de 1990 presenciou o nascimento e florescimento do Balanced Scorecard (KAPLAN; NORTON, 1992; 1993; 1996; 1997) que prega o alinhamento das estratégias como fundamental para o sucesso competitivo da empresa e utiliza quatro categorias de medidas: desempenho financeiro, conhecimento do cliente, processos internos, e aprendizado e crescimento.

$\mathrm{Na}$ década de 2000, surgiu o modelo de campos e armas da competição (CONTADOR, 2008), que alia duas concepções bastante distintas e que têm sido, de um modo geral, tratadas isoladamente na literatura especializada: a concepção de que a competitividade da empresa provém predominantemente do seu posicionamento no mercado, como pensa Porter, (posicionamento representado pelos campos da competição) e a concepção de que ela provém basicamente dos seus fatores internos, como postulam os autores adeptos da RBV (fatores denominados armas da competição). Portanto, a concepção 
do modelo de campos e armas da competição (CAC) é mais completa do que a de Porter e da RBV. Além dessa vantagem, o CAC é um modelo qualiquantitativo (trabalha também com variáveis numéricas), possui um pensamento central muito forte que orienta a formulação das estratégias competitivas e gera estratégias competitivas operacionais alinhadas à estratégia competitiva de negócio como postula o Balanced Scorecard (BSC).

Após comparar as metodologias do Planejamento Estratégico, de Porter, da RBV, do Balanced Scorecard e de campos e armas da competição, os autores resolveram testar a última para estudar a competitividade das concessionárias Chevrolet. Essa metodologia é fundamentada no modelo de campos e armas da competição de Contador (1995a; 1995b).

Várias razões justificam a escolha do modelo de campos e armas da competição:

$>$ é qualitativo e quantitativo, portanto mais apropriado para os objetivos da pesquisa do que os modelos de Porter e o da RBV, que são apenas qualitativos;

$>$ é adequado para analisar, explicar e ampliar o grau de competitividade de uma empresa e para formular sua estratégia competitiva;

$>$ separa nitidamente a visão externa da empresa, representada pelos campos onde ela compete, da visão interna, representada pelas armas que ela utiliza para competir;

$>$ utiliza o conceito de armas da competição, que dão origem às vantagens competitivas, diferente portanto da metodologia do Balanced Scorecard, baseada em indicadores, que são consequência da utilização das armas na operação empresarial;

$>$ é um modelo inovador, diferente dos usuais para o estudo da competitividade, e promissor, que deveria ser testado como uma alternativa aos modelos existentes; e

$>$ é de autor brasileiro, o que leva à suposição de ser mais adequado à realidade nacional.

Os objetivos específicos e as respectivas hipóteses do estudo são apresentados na terceira seção, após a exposição de alguns conceitos do modelo CAC feita na segunda seção, pois, sem esses conceitos, não é possível entendê-los. Os pontos da metodologia CAC relevantes para o presente artigo são apresentados ao longo do texto, iniciando na seção 4.

Segundo a taxonomia apresentada por Acevedo e Nohara (2004), a pesquisa nas concessionárias é explicativa e experimental, pois visa explicar, por meio de um experimento, as relações de causa e efeito, ou seja, identificar os fatores que explicam o fato de uma concessionária ser mais competitiva que outra. É uma pesquisa aplicada, pois gera conhecimentos pela aplicação prática a um problema específico, e também uma pesquisa quantitativa, pois traduz o problema por meio de variáveis numéricas que são avaliadas por métodos consagrados da Estatística Matemática.

Na pesquisa, foi utilizado o método popperiano dedutivo de prova (POPPER, 1968), segundo o qual, uma proposição só pode existir ser for devidamente formulada antes de ser testada pela experiência, por métodos sistemáticos de observação, que são derivados de enunciados singulares (no caso, os do modelo de campos e armas da competição). Por essa razão, foram formuladas previamente as hipóteses.

Atestam a relevância e a contribuição científicas deste artigo, a apresentação de uma nova metodologia de análise da competitividade empresarial e a aplicação ao setor de venda de peças de concessionárias de veículos. A originalidade e o ineditismo do estudo são comprovados pelo fato de não ter sido encontrado estudo semelhante na revisão da literatura.

\section{CONCEITOS SOBRE O MODELO DE CAMPOS E ARMAS DA COMPETIÇÃO}

Para o bom entendimento da metodologia, é necessário expor inicialmente os principais conceitos do modelo de campos e armas da competição (CAC), que foram lançados na Revista de Administração da USP em 1995 (CONTADOR, 1995a e 1995b). 
Apesar de Contador ter publicado em 2008 o livro Campos e Armas da Competição (CONTADOR, 2008), que engloba o referencial teórico a seguir mencionado, neste artigo foram mantidas várias citações da época da realização do estudo sobre as concessionárias Chevrolet.

\subsection{Os 17 campos da competição}

Campo da competição é um atributo de interesse do comprador, tal como qualidade do produto, preço e prazo de entrega. Eles constituem as estratégias competitivas de negócio que podem ser adotadas pela empresa, esgotando todas as possibilidades de diferenciação do produto. (CONTADOR, 1995a). Contador (2008) define campo da competição como o locus imaginário da disputa num mercado entre produtos ou entre empresas pela preferência do cliente, onde a empresa busca alcançar e manter vantagem competitiva.

Os 17 campos da competição, que são agrupados em cinco macrocampos, são:

competição em preço: 1 . em preço propriamente dito; 2. em guerra de preço; 3 . em prêmio ou promoção; e 4. em condições de pagamento;

$>$ competição em produto ou serviço: 5 . em projeto do produto; 6 . em qualidade do produto; 7. em variedade de modelos do produto; e 8. em produto inovador;

$>$ competição em atendimento: 9. em acesso ao atendimento; 10. em projeto do atendimento; 11. em qualidade do atendimento; 12. em variedade de atendimento; e 13. em atendimento inovador;

$>$ competição em prazo: 14 . em prazo de entrega; e 15. em prazo de atendimento; e

$>$ competição em imagem: 16 . competição em imagem do produto, da marca e da empresa; e 17. em imagem em responsabilidade social.

Uma das grandes vantagens desse modelo é a proposição de uma lista completa das possíveis estratégias competitivas, o que facilita sua formulação, pois a empresa passa a ter um referencial seguro de todas as possibilidades para se posicionar estrategicamente.

A decisão estratégica consiste na escolha de um ou dois campos principais e de um ou dois campos coadjuvantes para cada par produto/mercado. A expressão par produto/mercado é importante. Significa que não é a Ford que é concorrente da GM, mas sim que é um produto da Ford que é concorrente de um produto da GM, num certo mercado (CONTADOR, 2008).

\subsection{Armas da competição}

Arma da competição é uma ação ou um recurso utilizado pela empresa para alcançar vantagem competitiva, como marketing, tecnologia da informação e automação do processo produtivo. Contam-se às dezenas as armas da competição. Elas não interessam ao comprador: a ele, por exemplo, nada aproveita em conhecer o índice de rejeição; interessa-lhe, sim, a qualidade do produto (CONTADOR, 1995b).

Uma mesma arma serve para competir em mais de um campo e para competir num campo, são necessárias várias armas. Assim, automação do processo produtivo - uma arma é necessária, por exemplo, para um banco competir em preço ou em qualidade do atendimento. Se uma empresa industrial deseja competir em qualidade do produto - um campo - ela vai precisar de várias armas, como controle estatístico de processo, tecnologia adequada ao processo produtivo e melhoramento contínuo no processo (CONTADOR, 1995b).

\subsection{Estratégia competitiva de negócio e estratégia competitiva operacional}

Para o modelo CAC, definir a estratégia competitiva de negócio é decidir sobre os campos onde competir, e definir a estratégia competitiva operacional é decidir sobre quais 
armas da competição utilizar. A estratégia competitiva de negócio refere-se ao posicionamento de um produto no mercado, evidenciando a visão externa da empresa em relação aos clientes e aos concorrentes. A estratégia operacional, relativa aos departamentos da empresa, evidencia a visão interna da empresa, tratando do uso de armas que aumentam sua competitividade (CONTADOR, 2008).

2.4. O critério de competitividade do modelo de campos e armas da competição (CAC)

O modelo CAC dá um critério bastante seguro para a empresa ser competitiva: "Para a empresa ser competitiva, não há condição mais relevante do que ter excelência apenas nas armas que lhe dão vantagem competitiva no campo escolhido para competir em cada par produto/mercado" (CONTADOR, 1995b, p. 51). Essa afirmação dá o critério que falta em outros modelos: basta alinhar as armas aos campos escolhidos para cada par produto/mercado. As armas alinhadas ao campo são denominadas armas relevantes e são as que aumentam o grau de competitividade de um produto da empresa. Armas relevantes correspondem às competências essenciais de Prahalad e Hamel (1990; 1994; 1995).

Muitos autores afirmam, corretamente, que a empresa não deve procurar ser excelente em tudo. Mas, eles não especificam onde ser excelente. A grande vantagem do modelo CAC, no entender dos autores, está em especificar onde a empresa precisa ter excelência.

Esse critério simplifica e facilita a definição das estratégias competitivas operacionais da empresa. Uma vez escolhidos os campos (estratégia competitiva de negócio), estão automaticamente definidas as armas, pois "para cada campo de competição existem algumas armas adequadas" (CONTADOR, 1995b, p. 51). Assim, se esforços forem concentrados nas armas relevantes, a empresa aumentará o seu grau de competitividade.

Nota-se que, de certa maneira, os conceitos de CAC assemelham-se à "Visão Baseada em Recursos" (Resources Based View), pois a empresa pode criar vantagens competitivas a partir de seus recursos tangíveis e intangíveis (WERNERFELT, 1984; BARNEY, 1991; PETERAF, 1993; KROGH e ROSS, 1995; BARNEY, 2001).

\subsection{As variáveis quantitativas}

Para poder analisar quantitativamente a competitividade empresarial, o modelo CAC criou diversas variáveis matemáticas e trabalha com elas (CONTADOR e MEIRELES, 2001). Dessas, as cinco seguintes foram utilizadas na pesquisa objeto deste artigo.

$>$ Grau de competitividade da empresa é a variação de alguns indicadores de desempenho num determinado período de tempo. É uma variável contínua.

$>$ Intensidade da arma é a intensidade com que a arma é utilizada pela empresa, avaliada entre 1 e 5. É entendida também como o grau de eficácia da utilização dos recursos da arma ou a potência e alcance de uma arma. É uma variável discreta.

$>$ Intensidade média das armas é a média aritmética da intensidade de todas as armas pesquisadas. É uma variável contínua, com domínio entre 1 e 5.

$>$ Foco é a concentração de esforços nas armas relevantes para o campo da competição. Indica a utilização de armas que dão competitividade à empresa no escolhido campo da competição. É medido pela relação entre a soma da intensidade das armas relevantes e a soma da intensidade máxima possível de ser obtida em tais armas. É uma variável contínua, com domínio entre 0 e 1 . Quanto maior for a intensidade das armas relevantes, maior será o foco.

$>$ Dispersão é a aplicação de esforços nas armas irrelevantes para o campo da competição, representando dispersão de esforços. Indica a utilização de armas que não dão competitividade à empresa no campo escolhido, sendo o oposto do foco. É medida pela 
relação entre a soma da intensidade das armas irrelevantes e a soma da intensidade máxima possível de ser obtida em tais armas. É uma variável contínua, com domínio entre 0 e 1. Quanto maior for a intensidade das armas irrelevantes, maior será a dispersão.

\section{OBJETIVOS ESPECÍFICOS, HIPÓTESES E TESTES ESTATÍSTICOS}

Como mencionado, na pesquisa cujos resultados estão aqui relatados, foi utilizado o método popperiano dedutivo de prova (POPPER, 1968), segundo o qual, um enunciado geral (proposição, hipótese) só pode existir ser for devidamente formulado antes de ser testado pela experiência, por métodos sistemáticos de observação, que são derivados de enunciados singulares (no caso, os do modelo de campos e armas da competição).

A definição dos objetivos específicos e das hipóteses obedeceu à seguinte lógica:

1. a partir do objetivo geral, foram definidos os objetivos específicos;

2. para cada objetivo específico foi formulada pelo menos uma hipótese;

3. para cada hipótese foi definido pelo menos um teste estatístico;

4. pela validação estatística da hipótese, atingiu-se o respectivo objetivo específico;

5. validadas as hipóteses, ficou implicitamente validada a hipótese substantiva; e

6. uma vez alcançados os objetivos específicos, atingiu-se o objetivo geral.

Por essa lógica, os objetivos específicos e as hipóteses precisam gozar de absoluta coerência. Para obter essa coerência, foi construída a matriz de compatibilização entre objetivos, hipóteses e testes estatísticos, mostrada no Quadro 1.

No Quadro 1 estão apresentados: 1) o objetivo geral e suas respectivas hipóteses substantivas; e 2) os objetivos específicos e suas respectivas hipóteses. Os testes estatísticos serão mostrados ao longo deste artigo, na seção que tratará de cada objetivo específico.

Uma vez validadas as hipóteses relativas ao primeiro e segundo objetivos específicos, estão validadas as hipóteses substantivas e, portanto, atingido o primeiro objetivo da pesquisa. O segundo objetivo é alcançado por meio do terceiro objetivo específico

Quadro 1 - Matriz de compatibilização entre objetivos e hipóteses

\begin{tabular}{|c|c|}
\hline OBJETIVOS DA PESQUISA & HIPÓTESES SUBSTANTIVAS \\
\hline $\begin{array}{l}\text { 1. Investigar, por meio do modelo de campos } \\
\text { e armas da competição, os fatores que } \\
\text { determinam a competitividade do setor de } \\
\text { venda de peças das concessionárias Chevrolet. } \\
\text { 2. Recomendar medidas para aumentar o grau } \\
\text { de competitividade de uma concessionária } \\
\text { Chevrolet. }\end{array}$ & $\begin{array}{l}\text { 1. O alinhamento das armas aos campos da competição eleitos } \\
\text { pela empresa aumenta seu grau de competitividade. } \\
\text { 2. Para a empresa ser competitiva, não há condição mais } \\
\text { relevante do que ter excelência apenas nas poucas armas que lhe } \\
\text { dão vantagem competitiva no campo onde decidiu competir. } \\
\text { 3. O modelo CAC é suficiente para explicar e ampliar o grau de } \\
\text { competitividade da empresa. }\end{array}$ \\
\hline OBJETIVOS ESPECÍFICOS & HIPÓTESES \\
\hline $\begin{array}{l}\text { 1. Investigar a influência da estratégia } \\
\text { competitiva de negócio, representada pelos } \\
\text { campos da competição escolhidos pelas } \\
\text { empresas, na competitividade das empresas. }\end{array}$ & $\begin{array}{l}\text { 1. A estratégia competitiva de negócio não explica a diferença } \\
\text { de competitividade entre as empresas. } \\
\text { 2. Os campos da competição escolhidos pelas empresas mais } \\
\text { competitivas não são mais adequados ao consumidor do que os } \\
\text { escolhidos pelas menos competitivas. }\end{array}$ \\
\hline \multicolumn{2}{|c|}{ Hipótese estatística a testar - hipótese nula $\left(\mathrm{H}_{0}\right)$} \\
\hline \multicolumn{2}{|c|}{$\begin{array}{l}\text { Não há diferença significativa, pelo teste de Wilcoxon-Mann-Whitney com nível de significância de 5\%, entre os } \\
\text { campos da competição escolhidos pelas empresas mais competitivas e os escolhidos pelas menos competitivas. }\end{array}$} \\
\hline $\begin{array}{l}\text { 2. Investigar a influência da estratégia } \\
\text { competitiva operacional, representada pelas } \\
\text { variáveis intensidade média das armas, foco e } \\
\text { dispersão, na competitividade das empresas. }\end{array}$ & $\begin{array}{l}\text { 1. A estratégia competitiva operacional explica a diferença de } \\
\text { competitividade entre as empresas. } \\
\text { 2. As empresas que possuem maior foco são mais competitivas. } \\
\text { 3. A intensidade média das armas e a dispersão não influenciam }\end{array}$ \\
\hline
\end{tabular}


a competitividade das empresas.

1. Há correlação muito forte, medida pelo índice de correlação de Pearson, entre o foco das armas no campo da competição da empresa e o seu grau de competitividade.

2. A média do foco das armas no campo da competição escolhido pelas empresas mais competitivas é significativamente maior do que a média do foco das menos competitivas, segundo o teste $t$ com nível de significância de $5 \%$.

3. Não há correlação, medida pelo índice de correlação de Pearson, entre a dispersão das armas da empresa e o seu grau de competitividade.

4. A média da dispersão das armas no campo da competição escolhido pelas empresas mais competitivas não é significativamente maior do que a média da dispersão das menos competitivas, segundo o teste $t$ com nível de significância de $5 \%$.

5. Não há correlação, medida pelo índice de correlação de Pearson, entre a intensidade média das armas da empresa e o seu grau de competitividade.

6. A média da intensidade média das armas das empresas mais competitivas é significativamente maior do que a média das menos competitivas, segundo o teste $t$ com nível de significância de $5 \%$.

3. Recomendar medidas para aumentar o grau Para aumentar o grau de competitividade de uma empresa, basta de competitividade de uma empresa e avaliar redirecionar os investimentos, passando para as armas o aumento no seu grau de competitividade relevantes os investimentos previstos nas armas irrelevantes.

Fonte: Autores

\section{A METODOLOGIA DO ESTUDO}

A metodologia adotada para a realização do estudo, que é fundamentada no modelo de campos e armas da competição, é constituída por cinco etapas, cada uma contendo vários passos:

$1^{\text {a }}$ etapa: Elaboração do projeto de pesquisa, contendo os passos: 1) Fixação dos objetivos da pesquisa e formulação das hipóteses; 2) Definição do critério de cálculo do grau de competitividade; 3) Seleção e descrição das armas; e 4) Preparação dos questionários;

$2^{\text {a }}$ etapa: Cálculo do grau de competitividade, contendo os passos: 1) Cálculo do grau de competitividade; e 2) Classificação das empresas em mais competitivas e menos competitivas; $3^{a}$ etapa: Análise das estratégias competitivas de negócio, contendo os passos: 1) Identificação das estratégias competitivas por meio da identificação dos campos da competição escolhidos pelas empresas; e 2) Verificação da existência de diferença significativa entre as estratégias.

$4^{\text {a }}$ etapa: Análise das estratégias competitivas operacionais, contendo os passos: 1) Classificação das armas em relevantes, neutras e irrelevantes; 2) Cálculo da intensidade média das armas, do foco e da dispersão para o campo da competição de cada empresa; 3) Análise da influência do foco e da dispersão da empresa na sua competitividade; e 4) Análise da influência da intensidade média das armas na competitividade.

5 etapa: Recomendação de medidas para aumentar a competitividade de uma empresa.

A seguir será exposto como essa metodologia foi aplicada às concessionárias.

\subsection{Primeira Etapa: Elaboração Do Projeto De Pesquisa}

O objetivo desta etapa foi planejar os trabalhos e preparar os questionários.

Passo 1: Fixação dos objetivos da pesquisa e formulação das hipóteses

Os objetivos da pesquisa e as respectivas hipóteses foram mostrados na seção 3 .

Passo 2: Definição do critério de cálculo do grau de competitividade

Há três linhas predominantes de pensamento para medir o grau de competitividade de uma empresa. São elas: por indicadores financeiros, como a rentabilidade, por indicador de participação de mercado ou por vários indicadores de desempenho, como faz o Balanced 
Scorecard. O modelo CAC utiliza simultaneamente os dois primeiros. Entretanto, na pesquisa que ilustra este trabalho, diante da dificuldade em obter informações sobre indicadores financeiros das empresas, utilizou-se somente a participação de mercado.

Assim, o grau de competitividade foi calculado pela variação percentual do faturamento da empresa no período de cinco anos, entre 2000 e 2005.

\section{Passo 3: Seleção e descrição das armas}

Como são muitas as armas utilizadas por uma empresa, é conveniente inicialmente selecionar as mais importantes, de maneira a simplificar o trabalho de análise.

A natureza, a importância e o conteúdo das várias ações e recursos utilizados pela empresa determinam o conjunto das armas da competição da empresa. A relevância de uma arma da competição determina se ela será utilizada para competir num certo campo. Depreende-se, então, que há duas classificações a serem consideradas: a classificação das armas segundo sua natureza, importância e conteúdo e a classificação segundo a relevância para o campo escolhido para competir.

Analisando a natureza, a importância e o conteúdo das várias ações e recursos utilizados pelo setor de peças das concessionárias Chevrolet, foram selecionadas, dentre a centena de armas utilizada, as 51 armas da competição, mostradas na Tabela 3. O método para determinar a relevância de uma arma para um campo da competição é mostrado na seção 8.1.

\section{Passo 4: Preparação dos questionários}

A partir dos passos anteriores, foram preparados três questionários: o Questionário 1 para coletar as informações gerais da empresa (identificação e variação percentual do faturamento anual entre 2000 e 2005, utilizado para o cálculo do grau de competitividade); o Questionário 2 sobre os campos onde a empresa compete no setor de peças; e o Questionário 3 sobre a intensidade das armas da competição utilizadas pela empresa.

Visto que o modelo CAC é quantitativo, é necessário avaliar a intensidade de cada arma. Como já foi definido, intensidade da arma é a intensidade com que a arma da competição é utilizada ou o grau de eficácia da utilização dos recursos da arma. A intensidade da arma é avaliada entre 1 e 5, sendo, pois, uma variável discreta.

Para que as concessionárias Chevrolet pudessem avaliar a intensidade de cada arma, no Questionário 3 foram definidos o significado e o conteúdo de cada uma das 51 armas da competição. O Quadro 2 mostra as armas 11 e 12 do Questionário 3.

A análise de viés constatou homogeneidade dessas concessionárias, de maneira que todas integraram o universo amostral.

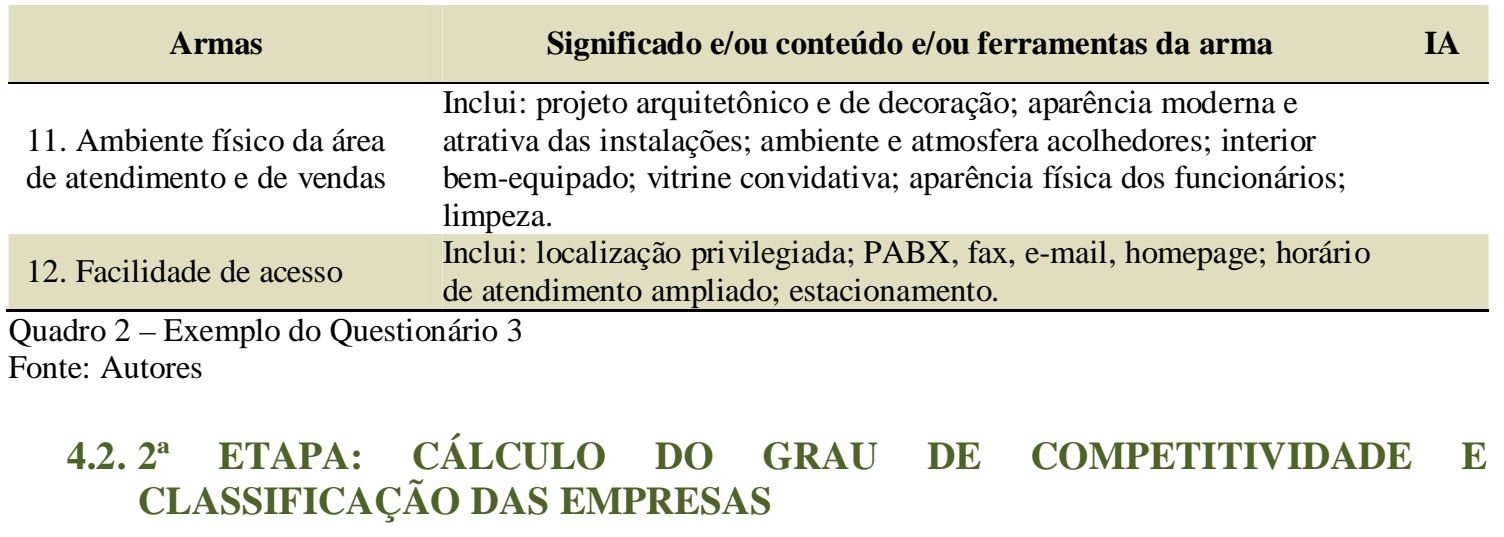

\section{Passo 1: Cálculo do grau de competitividade}




\section{METODOLOGIA DE CAMPOS E ARMAS DA COMPETIÇÃO APLICADA AO ESTUDO DA COMPETITIVIDADE DE CONCESSIONÁRIAS CHEVROLET}

O grau de competitividade de cada empresa foi calculado pela variação percentual do seu faturamento no período de cinco anos, entre 2000 e 2005 :

[(faturamento 2005/faturamento 2000)] x 100, cujo resultado está na Tabela 1.

\section{Passo 2: Classificação das empresas em mais competitivas e menos competitivas}

Essa classificação serve para verificar se há diferença entre as estratégias competitivas, de negócio e operacionais, adotadas pelas empresas mais competitivas em relação às estratégias adotadas pelas empresas menos competitivas. Assim, as 13 concessionárias foram classificadas decrescentemente pelo grau de competitividade e agregadas em três classes: empresas mais competitivas, menos competitivas e de mediana competitividade.

Para a agregação nessas três classes, o modelo CAC recomenda a utilização do índice de Nihans, cujo procedimento está na seção 8.1. Apesar dessa recomendação, no caso desta pesquisa foi possível identificar claramente duas classes, a das empresas mais competitivas e a das menos competitivas, sem necessidade de usá-lo, como se pode notar na Tabela 1. Isso só foi possível porque o grau de competitividade das empresas distribuía-se convenientemente.

Assim, a classe das empresas mais competitivas é constituída pelas empresas cujo grau de competitividade é superior a 174, e a classe das menos competitivas pelas empresas cujo grau de competitividade é inferior a 137, como mostra a Tabela 1.

A fim de dar rigor às análises que serão feitas, é necessário verificar se efetivamente há diferença significativa entre o grau de competitividade das empresas mais competitivas e o grau de competitividade das empresas menos competitivas. Essa verificação foi feita por meio do teste $t$, que compara a média $(185,88)$ do grau de competitividade das empresas mais competitivas com a média $(122,40)$ das menos competitivas, supondo que os desvios-padrão das duas amostras são desconhecidos e diferentes entre si. Esse caso é o que imprime maior rigor à comparação. A hipótese nula $\left(\mathrm{H}_{0}\right)$ supõe a igualdade das duas médias, e a hipótese alternativa supõe que a média do grau de competitividade das empresas mais competitivas é maior que a média das menos competitivas, acarretando, portanto, um teste unicaudal. O teste $\mathrm{t}$ é baseado na distribuição $\mathrm{t}$ de Student, aplicável a pequenas amostras. Seu resultado, mostrado na Tabela 4, permitiu rejeitar a hipótese nula com nível de significância de 0,00002 , o que permite afirmar, com 99,99\% de confiança, que o grau de competitividade das empresas mais competitivas é maior que o grau de competitividade das empresas menos competitivas.

Para comparar as médias de duas populações utilizando o teste t, é necessária, a rigor, a satisfação de duas condições: $1^{\mathrm{a}}$ ) as amostras devem ser independentes; e $2^{\mathrm{a}}$ ) a média das amostras deve ter distribuição normal. A independência entre as amostras é facilmente verificada, pois não há relação entre as empresas. A segunda condição foi confirmada pela aplicação do teste de Kolmogorov-Smirnov sobre os elementos da amostra.

\section{3. $3^{\text {a }}$ ETAPA: ANÁLISE DAS ESTRATÉGIAS COMPETITIVAS DE NEGÓCIO}

Esta etapa refere-se ao primeiro objetivo específico formulado na seção 3 .

\section{Passo 1: Identificação das estratégias competitivas}

As estratégias competitivas de negócio diferenciam as empresas mais competitivas das menos competitivas? Para responder a essa questão, é necessário, inicialmente, identificá-las, depois classificá-las, para em seguida verificar se há diferença significativa entre as estratégias de negócio das empresas mais competitivas e as das empresas menos competitivas.

A identificação foi feita a partir das respostas ao segundo questionário, que solicitou às empresas que indicassem, entre os 17 campos, a alternativa que expressasse, para seu principal produto, o campo no qual buscam conquistar ou manter sua vantagem competitiva. 
Os três campos da competição declarados pelas empresas foram: $1^{\circ}$ ) qualidade de atendimento (seis empresas); $2^{\circ}$ ) prazo de entrega (quatro empresas); e $3^{\circ}$ ) menor preço (três empresas). Esses campos da competição estão na Tabela 1, assim como os coadjuvantes.

Tabela 1 - Grau de competitividade e campos declarados

\begin{tabular}{|c|c|c|c|c|}
\hline Empresa & GC & Campo competição & Campo coadjuvante & Empresas \\
\hline E05 & 198 & Qualidade do atendimento & Condições de pagamento & \multirow{8}{*}{ Mais competitivas } \\
\hline E03 & 195 & Qualidade do atendimento & Variedade de atendimento & \\
\hline E11 & 192 & Prazo de entrega & Preço menor & \\
\hline E08 & 188 & Qualidade atendimento & Imagem do produto & \\
\hline E01 & 185 & Prazo de entrega & Qualidade do atendimento & \\
\hline E04 & 180 & Preço menor & Acesso ao atendimento & \\
\hline E13 & 175 & Preço menor & Condições de pagamento & \\
\hline E12 & 174 & Prazo de entrega & Qualidade do atendimento & \\
\hline E02 & 137 & Prazo de entrega & Qualidade do atendimento & \multirow{5}{*}{ Menos competitivas } \\
\hline E07 & 131 & Qualidade do atendimento & Condições de pagamento & \\
\hline E06 & 123 & Qualidade do atendimento & Acesso ao atendimento & \\
\hline E09 & 115 & Qualidade do atendimento & Preço menor & \\
\hline E10 & 106 & Preço menor & Condições de pagamento & \\
\hline
\end{tabular}

\section{Passo 2: Verificação da existência de diferença significativa entre as estratégias}

Para analisar se há diferença entre as estratégias competitivas de negócio das empresas mais competitivas e as das menos competitivas, é necessário verificar se há diferença significativa com relação aos campos da competição dessas duas classes de empresas.

Comparando o conjunto dos campos da competição das empresas mais competitivas com o conjunto das menos competitivas, pode-se intuir que não há diferença entre ambos (vide Tabela 1). No entanto, para dar tratamento estatístico, utilizou-se o teste de WilcoxonMann-Whitney, um teste não paramétrico útil para verificar a identidade de duas populações a partir da soma dos postos dos valores observados (MENDENHALL, 1963).

O posto de um valor em um conjunto de $n$ valores é o número que indica sua posição no conjunto ordenado do primeiro ao n-ésimo valor. Para aplicar o teste, a hipótese nula $\left(\mathrm{H}_{0}\right)$ adotada é a igualdade entre os dois conjuntos de estratégias competitivas. Wilcoxon considerou que, sendo válida a hipótese $\mathrm{H}_{0}$, as somas dos postos nas amostras deveriam fornecer valores intermediários compatíveis com o tamanho de cada amostra. Mann e Whitney desenvolveram um procedimento para o teste baseado no cálculo de qualquer uma das quantidades:

$$
\mathrm{u}_{1}=\mathrm{n}_{1} \cdot \mathrm{n}_{2}+\frac{\mathrm{n}_{1}\left(\mathrm{n}_{1}+1\right)}{2}-\mathrm{T}_{1} \quad \text { ou } \quad \mathrm{u}_{2}=\mathrm{n}_{1} \cdot \mathrm{n}_{2}+\frac{\mathrm{n}_{2}\left(\mathrm{n}_{2}+1\right)}{2}-\mathrm{T}_{2}
$$

onde:

$\mathrm{n}_{1}$ e $\mathrm{n}_{2}$ são o tamanho das duas amostras; e

$\mathrm{T}_{1}$ e $\mathrm{T}_{2}$ as respectivas soma dos postos.

Para $n_{1}>7$ e $n_{2}>7$, admite-se que as variáveis $u_{1}$ ou $u_{2}$ possuem distribuição normal, sendo que para $\mathrm{H}_{0^{-}}$verdadeira tem-se: 


$$
\mu\left(u_{1}\right)=\mu\left(u_{2}\right)=\frac{n_{1} \cdot n_{2}}{2} \text { e } \sigma\left(u_{1}\right)=\sigma\left(u_{2}\right)=\sqrt{\frac{n_{1} \cdot n_{2}\left(n_{1}+n_{2}+1\right)}{12}}
$$

Assim, utilizando-se os valores $\mathrm{u}_{1}$ ou $\mathrm{u}_{2}$, é possível construir o seguinte teste:

$$
\mathrm{z}=\frac{\mathrm{u}_{1}-\mu(\mathrm{u})}{\sigma(\mathrm{u})}
$$

As estratégias competitivas de negócio adotadas pelas empresas, representadas pelos campos da competição, estão na terceira coluna da Tabela 1: $1^{\circ}$ ) qualidade do atendimento (seis empresas); $2^{\circ}$ ) prazo de entrega (quatro empresas); e $3^{\circ}$ ) menor preço (três empresas).

Como o campo qualidade do atendimento aparece seis vezes, seus postos são: 1, 2, 3, 4, 5 e 6 , que devem ser substituídos pelo posto médio: $[(1+2+3+4+5+6) / 6]=3,5$.

Como o campo prazo de entrega aparece quatro vezes, seus postos são: 7, 8, 9 e 10. Assim, esses postos devem ser substituídos pelo posto médio: $[(7+8+9+10) / 4]=8,5$.

Como o campo preço aparece três vezes, seus postos são: 11,12 e 13. Assim, esses postos devem ser substituídos pelo posto médio: $[(11+12+13) / 3]=12,0$.

Tabela 2 - Postos dos campos da competição para o teste de Wilcoxon-Mann-Whitney

\begin{tabular}{llcc}
\multicolumn{2}{c}{ CAMPOS DA COMPETIÇÃO } & \multicolumn{2}{c}{ POSTOS } \\
\hline \multicolumn{1}{c}{$\begin{array}{c}\text { Empresas mais } \\
\text { competitivas }\end{array}$} & \multicolumn{1}{c}{$\begin{array}{c}\text { Empresas menos } \\
\text { competitivas }\end{array}$} & $\begin{array}{c}\text { Empresas mais } \\
\text { competitivas }\end{array}$ & $\begin{array}{c}\text { Empresas menos } \\
\text { competitivas }\end{array}$ \\
$\begin{array}{l}\text { Qualidade do } \\
\text { atendimento }\end{array}$ & Prazo de entrega & 3,5 & 8,5 \\
\hline $\begin{array}{l}\text { Qualidade do } \\
\text { atendimento }\end{array}$ & Qualidade do atendimento & 3,5 & 3,5 \\
Prazo de entrega & Qualidade do atendimento & 8,5 & 3,5 \\
\hline $\begin{array}{l}\text { Qualidade do } \\
\text { atendimento }\end{array}$ & Qualidade do atendimento & 3,5 & 3,5 \\
Prazo de entrega & Preço menor & 8,5 & 12,0 \\
\hline Preço menor & & 12,0 & \\
\hline Preço menor & & 12,0 & \\
\hline Prazo de entrega & $\mathrm{N}_{2}=5$ & 8,5 & $\mathrm{~T}_{2}=31$ \\
\hline \multicolumn{1}{c}{$\mathrm{N}_{1}=8$} & & $\mathrm{~T}_{1}=60,0$ & \\
\hline
\end{tabular}

Fonte: Autores

Com os dados da Tabela 2, calculam-se:

$\mu\left(u_{1}\right)=\frac{8 x 5}{2}=20,0 ; \quad \sigma\left(u_{1}\right)=\sqrt{\frac{8 x 5 x(8+5+1)}{12}}=6,90 ; \quad u_{1}=8 x 5+\frac{8(8+1)}{2}-60,0=16,0$

$u_{2}=8 x 5+\frac{5(5+1)}{2}-31,0=24,0$

Note-se que a média dos postos das empresas mais competitivas $(16,0)$ e a média dos postos das menos competitivas (24) são equidistantes da média das 13 empresas $(20,0)$. Isso significa que a média das duas médias é igual à média geral: $[(16+24) / 2]=20$.

Finalmente $\quad z=\frac{16,0-20,0}{6,90}=-0,580 \quad$ ou $\quad z=\frac{24,0-20,0}{6,90}=0,580$

Usualmente se adota o nível de significância de 5\% (2,5\% em cada cauda, teste bicaudal), que corresponde na distribuição normal ao valor de $\mathrm{z}=1,96$. Como o valor de $\mathrm{z}$ 
encontrado (0,580 em valor absoluto) é menor do que 1,96, não é possível rejeitar a hipótese nula $\mathrm{H}_{0}$. Portanto, ela é aceita. Assim, conclui-se que não há diferença, ao nível de significância de 5\%, entre os campos da competição escolhidos pelas empresas mais competitivas e os escolhidos pelas menos competitivas.

Aplicando o teste de Wilcoxon-Mann-Whitney, agora para os campos coadjuvantes, obtém-se $\mathrm{z}=-0,290$. Analogamente ao teste com os campos da competição, não é possível rejeitar a hipótese nula $\mathrm{H}_{0}$. Portanto, ela é aceita. Assim, conclui-se também que não há diferença, ao nível de significância de 5\%, entre os campos coadjuvantes escolhidos pelas empresas mais competitivas e os escolhidos pelas menos competitivas.

\subsection{Conclusão sobre as estratégias competitivas de negócio}

Pelos dois testes estatísticos anteriores, conclui-se que não há diferença, ao nível de significância de 5\%, tanto entre os campos da competição quanto entre os campos coadjuvantes das empresas mais competitivas e os das menos competitivas. Portanto,

1. aceita-se a primeira hipótese do Quadro 1, qual seja, a estratégia competitiva de negócio não explica a diferença de competitividade entre as empresas; e

2. aceita-se a segunda hipótese do Quadro 1, qual seja, os campos da competição escolhidos pelas empresas mais competitivas não são mais adequados ao consumidor do que os escolhidos pelas menos competitivas.

Conclui-se então que as empresas mais competitivas e as menos competitivas adotam as mesmas estratégias competitivas de negócio. Isso significa que as empresas têm percepção muito semelhante sobre os campos, tanto os da competição quanto os coadjuvantes, valorizados pelos clientes.

Pode parecer estranho que as estratégias competitivas não expliquem a diferença no grau de competitividade das empresas. Mas essa conclusão é coerente com os resultados de outras pesquisas realizadas por meio do modelo CAC.

Como se verá adiante, são as estratégias competitivas operacionais que explicam a diferença no grau de competitividade das empresas. Mais especificamente as empresas que possuem estratégias competitivas operacionais melhor alinhadas com as estratégias competitivas de negócio.

\section{5. $4^{\text {a }}$ ETAPA: ANÁLISE DAS ESTRATÉGIAS COMPETITIVAS OPERACIONAIS}

A análise das estratégias competitivas operacionais, adotadas pelas concessionárias Chevrolet no setor de peças, refere-se ao segundo objetivo específico formulado na seção 3 .

\section{Passo 1: Classificação das armas em relevantes, neutras e irrelevantes}

Para calcular as variáveis foco e dispersão é necessário classificar as armas em relevantes, irrelevantes e neutras para a competitividade. Para isso, utilizou-se a matriz de priorização das armas e o índice de Nihans. A matriz de priorização é uma matriz quadrada contendo todas as armas em análise nas linhas e todas na coluna (no caso, as 51 armas). Como uma mesma arma pode ser relevante para um campo da competição e irrelevante para outro, é necessário construir uma matriz de priorização para cada campo. Em cada matriz, é adotado o procedimento descrito em De Sordi e Contador (2006) publicado na RAUSP.

A classificação das armas em relevantes, neutras e irrelevantes é mostrada nas terceira e quarta colunas, Relevante e Irrelevante, da Tabela 3. Valores 1 e 0 , respectivamente nessas duas colunas, significam que a arma da linha é relevante, portanto aumenta o foco; valores 0 e 1 significam que a arma é irrelevante, portanto aumenta a dispersão; e valores 0 e 0 nessas duas colunas significam que a arma é neutra. 


\section{Passo 2: Cálculo da intensidade média das armas, do foco e da dispersão}

A Tabela 3 ilustra o cálculo, feito numa planilha Excel, das três variáveis para a empresa E13, que declarou competir em preço (vide colunas Relevante e Irrelevante).

A primeira e a segunda colunas da Tabela 3 mostram as armas da competição selecionadas, conforme exposto na seção 5.3. Essas colunas são iguais para todas as empresas.

A terceira e a quarta colunas da Tabela 3 são tiradas diretamente da matriz de priorização das armas, conforme o procedimento apresentado na seção 8.1. Ressalte-se que essas colunas são idênticas para todas as empresas que competem em preço e diferentes para os outros campos. Isso porque cada campo da competição possui um conjunto próprio de armas relevantes e outro conjunto de armas irrelevantes, decorrente do fato de que para cada campo é construída uma matriz de priorização das armas.

$\mathrm{Na}$ quinta coluna da planilha é anotado o valor da intensidade de cada arma avaliada pela empresa E13, conforme dados coletados por meio do Questionário 3 - Avaliação da Intensidade Atual das Armas. A intensidade média das armas (vide última linha da planilha) é a média aritmética da intensidade de todas as armas.

A sexta coluna da Tabela 3, Foco, resulta da multiplicação da terceira coluna pela quinta. Conforme sua definição, o valor do foco $(0,862)$ resulta da soma dos valores da sexta coluna (56) dividida pelo produto da soma da terceira coluna (13) por 5: [56/(13 x 5)] = 0,862. (A terceira coluna mostra as armas relevantes, obtidas diretamente da matriz de priorização das armas, conforme exposição da seção anterior). Como se nota, o foco corresponde à média das armas relevantes dividida por 5 (5, por definição, é o valor máximo que a intensidade de uma arma pode assumir).

O valor da dispersão é obtido de forma análoga. A sétima coluna da Tabela 3, Dispersão, resulta da multiplicação da quarta coluna pela quinta. O valor da dispersão $(0,686)$ é obtido pela soma dos valores da sétima coluna (96) dividida pelo produto da soma dos valores da quarta coluna (28) por 5. (A quarta coluna mostra as armas irrelevantes, obtidas diretamente da matriz de priorização das armas).

\section{Passo 3: Análise da influência do foco e da dispersão das armas na competitividade da concessionária}

A análise estatística da competitividade das empresas foi feita por meio da correlação de Pearson e do teste t. Tomou-se sempre o cuidado de usar a distribuição t de Student, aplicável a pequenas amostras, e de verificar as duas condições necessárias para a aplicação do teste $t$, conforme as razões expostas na seção 6.2 , quais sejam: $1^{a}$ ) as amostras devem ser independentes; e $2^{\mathrm{a}}$ ) a média das amostras deve ter distribuição normal. 
Tabela 3 - Cálculo da intensidade média das armas, do foco e da dispersão para o campo preço declarado pela empresa E13

Cálculo da Intensidade média das armas, do foco e da difusão para o campo da competição

\begin{tabular}{|c|c|c|c|c|c|c|}
\hline \multicolumn{2}{|r|}{ Número da empresa respondente } & E13 & \multicolumn{2}{|c|}{ Grau de competividade } & \multirow{2}{*}{\multicolumn{2}{|c|}{$\begin{array}{c}175 \\
\text { Pontuação }\end{array}$}} \\
\hline № & Armas da competição & \multicolumn{2}{|c|}{ Preço } & \multirow[t]{2}{*}{$\begin{array}{c}\text { Intensidade } \\
\text { da arma }\end{array}$} & & \\
\hline & FORMULAÇÃO ESTRATÉGIA E MARKETING & Relevante & Irrelevante & & Foco & Dispersãı \\
\hline 1 & Sistema de inteligência competitiva & 0 & 0 & 5 & 0 & 0 \\
\hline 2 & Formulação da estratégia & 0 & 0 & 5 & 0 & 0 \\
\hline 3 & Responsabilidade Social & 0 & 1 & 4 & 0 & 4 \\
\hline 4 & Adequação do plano de consórcio ao cliente & 0 & 1 & 2 & 0 & 2 \\
\hline 5 & Estratégia e administração de marketing & 0 & 0 & 3 & 0 & 0 \\
\hline 6 & Pesquisa de mercado & 1 & 0 & 4 & 4 & 0 \\
\hline 7 & Publicidade e propaganda (em diversas mídias) & 1 & 0 & 4 & 4 & 0 \\
\hline 8 & Comunicação Visual & 0 & 1 & 5 & 0 & 5 \\
\hline 9 & Marketing direto & 0 & 1 & 4 & 0 & 4 \\
\hline 10 & Marketing de relacionamento & 0 & 1 & 2 & 0 & 2 \\
\hline & ATENDIMENTO AO CLIENTE & & & & & \\
\hline 11 & Ambiente físico da área de atendimento e de vendas & 0 & 1 & 5 & 0 & 5 \\
\hline 12 & Facilidade de acesso & 0 & 1 & 5 & 0 & 5 \\
\hline 13 & Administração de vendas & 0 & 0 & 5 & 0 & 0 \\
\hline 14 & Sistema de informação de vendas & 0 & 0 & 5 & 0 & 0 \\
\hline 15 & Equipe agressiva de vendas & 1 & 0 & 4 & 4 & 0 \\
\hline 16 & Equipe técnica de vendas & 1 & 0 & 5 & 5 & 0 \\
\hline 17 & Rapidez no atendimento & 0 & 1 & 5 & 0 & 5 \\
\hline 18 & Disponibilização de serviços complementares & 0 & 1 & 3 & 0 & 3 \\
\hline 19 & Assistência técnica & 0 & 1 & 4 & 0 & 4 \\
\hline 20 & Cortesia no atendimento & 0 & 0 & 3 & 0 & 0 \\
\hline 21 & Adequação do atendimento ao cliente & 0 & 0 & 4 & 0 & 0 \\
\hline 22 & Uniformidade e consistência do atendimento & 0 & 0 & 4 & 0 & 0 \\
\hline 23 & SAC - Serviço de atendimento ao consumidor & 0 & 1 & & 0 & 0 \\
\hline 24 & Relacionamento com cliente & 0 & 1 & 3 & 0 & 3 \\
\hline 25 & Monitoramento da satisfação do cliente & 0 & 1 & 4 & 0 & 4 \\
\hline 26 & Atendimento especial para clientes VIP & 0 & 1 & 4 & 0 & 4 \\
\hline 27 & Empresa virtual & 1 & 0 & 5 & 5 & 0 \\
\hline 28 & Influência sobre clientes em potencial & 0 & 1 & 5 & 0 & 5 \\
\hline & PROJETO DE PRODUTO & & & & & \\
\hline 29 & Monitoramento das tendências e novidades do produto & 0 & 1 & 0 & 0 & 0 \\
\hline 30 & Identificação dos requisitos do cliente & 0 & 1 & 0 & 0 & 0 \\
\hline 31 & Definição do conceito ( concepção) do produto & 0 & 1 & 0 & 0 & 0 \\
\hline 32 & Avaliação do produto & 0 & 1 & 0 & 0 & 0 \\
\hline & PROCESSO ADMINISTRATIVO & & & & & \\
\hline 33 & Definição da estrutura de poder & 0 & 0 & 4 & 0 & 0 \\
\hline 34 & Ambiente físico das áreas administrativas & 0 & 1 & 4 & 0 & 4 \\
\hline 35 & Sistema de informação interno & 0 & 1 & 5 & 0 & 5 \\
\hline 36 & Sistema de informação gerencial & 1 & 0 & 5 & 5 & 0 \\
\hline 37 & Sistema de informação operacional & 1 & 0 & 5 & 5 & 0 \\
\hline 38 & Processo de decisção gerencial e operacional & 1 & 0 & 4 & 4 & 0 \\
\hline 39 & Programa de melhoria de qualidade & 0 & 0 & 5 & 0 & 0 \\
\hline 40 & Rapidez de produção dos serviços & 0 & 1 & 5 & 0 & 5 \\
\hline 41 & Programa permanente de redução de custo & 1 & 0 & 4 & 4 & 0 \\
\hline 42 & Planejamento de recursos humanos & 0 & 1 & 4 & 0 & 4 \\
\hline 43 & Capacitação de pessoal & 0 & 1 & 5 & 0 & 5 \\
\hline 44 & Sistema de avaliação de pessoal & 0 & 1 & 5 & 0 & 5 \\
\hline 45 & Administração participativa & 0 & 1 & 5 & 0 & 5 \\
\hline 46 & Motivação de pessoal & 0 & 1 & 4 & 0 & 4 \\
\hline 47 & Sistema de recompensas ou Política de salários & 0 & 1 & 4 & 0 & 4 \\
\hline 48 & Estabelecimento de metas aos funcionários & 1 & 0 & 4 & 4 & 0 \\
\hline 49 & Gerentes e funcionários empreendedores & 1 & 0 & 4 & 4 & 0 \\
\hline 50 & Administração financeira & 1 & 0 & 4 & 4 & 0 \\
\hline 51 & Controladoria estratégica & 1 & 0 & 4 & 4 & 0 \\
\hline & Soma & 13 & 28 & 195 & 56 & 96 \\
\hline & Intensidade média das armas, foco e difusão & & & 3,824 & 0,862 & 0,686 \\
\hline
\end{tabular}

Fonte: Autores 


\section{METODOLOGIA DE CAMPOS E ARMAS DA COMPETIÇÃO APLICADA AO ESTUDO DA COMPETITIVIDADE DE CONCESSIONÁRIAS CHEVROLET}

Conforme mostra a Tabela 4, o índice de correlação de Pearson (r) entre o grau de competitividade e o foco das armas no campo da competição das empresas da amostra é 0,89, o que representa associação positiva muito forte (r próximo de 0,90 ) entre essas variáveis. Este resultado é bastante significativo, evidenciando que a variável foco explica, sozinha, $79 \%\left(\mathrm{r}^{2}=0,89^{2}=0,79\right)$ da variação do faturamento da empresa. Assim, para o setor de peças das concessionárias Chevrolet, segundo os resultados da pesquisa, se a empresa se concentrar nas armas relevantes, aquelas que contribuem para a variável foco, estará gerenciando $79 \%$ dos fatores que afetam seu faturamento.

O foco médio das armas no campo da competição escolhido pelas empresas mais competitivas $(0,851)$ é maior, ao nível de significância de $0,002(0,2 \%)$, do que o foco médio das empresas menos competitivas $(0,745)$. Portanto, conclui-se, com $99,8 \%$ de confiança, que as empresas mais competitivas têm foco maior que as menos competitivas.

Conforme mostra também a Tabela 4, o índice de correlação entre o grau de competitividade e a dispersão das armas no campo da competição escolhido pelas empresas é 0,254. O teste de correlação linear de Pearson (COSTA NETO, 1977, p. 186) constatou que, para uma amostra de 13 elementos, só há correlação, ao nível de significância de 5\%, para os valores do índice de correlação superiores a 0,55. Portanto, não se pode afirmar com confiança de $95 \%$ que há correlação entre a dispersão e o grau de competitividade das empresas. Em outras palavras, a dispersão não influencia a competitividade das empresas.

Tabela 4 - Intensidade média das armas, foco e dispersão: correlação e teste t

\begin{tabular}{|c|c|c|c|c|c|}
\hline Empresa & GC & IMA & Foco & Dispersão & Empresas \\
\hline E05 & 198 & 4,353 & 0,892 & 0,754 & \multirow{8}{*}{$\begin{array}{c}\text { Mais } \\
\text { competitivas }\end{array}$} \\
\hline E03 & 195 & 3,608 & 0,877 & 0,354 & \\
\hline E11 & 192 & 4,059 & 0,913 & 0,625 & \\
\hline E08 & 188 & 3,647 & 0,838 & 0,600 & \\
\hline E01 & 185 & 4,078 & 0,825 & 0,788 & \\
\hline E04 & 180 & 4,039 & 0,800 & 0,807 & \\
\hline E13 & 175 & 3,824 & 0,862 & 0,686 & \\
\hline E12 & 174 & 3,314 & 0,800 & 0,538 & \\
\hline E02 & 137 & 3,549 & 0,788 & 0,413 & \multirow{15}{*}{$\begin{array}{c}\text { Menos } \\
\text { competitivas }\end{array}$} \\
\hline E07 & 131 & 3,098 & 0,746 & 0,415 & \\
\hline E06 & 123 & 3,941 & 0,792 & 0,692 & \\
\hline E09 & 115 & 3,529 & 0,723 & 0,492 & \\
\hline E10 & 106 & 3,510 & 0,677 & 0,657 & \\
\hline Média de todas as empresas & 161,46 & 3,735 & 0,810 & 0,602 & \\
\hline Desvio-padrão de todas as empresas & 33,63 & 0,351 & 0,068 & 0,149 & \\
\hline Média das empresas mais competitivas & 185,88 & 3,8652 & 0,851 & 0,644 & \\
\hline Desvio-padrão das mais competitivas & 9,00 & 0,3317 & 0,042 & 0,1507 & \\
\hline Média das empresas menos competitivas & 122,40 & 3,5254 & 0,745 & 0,5338 & \\
\hline Desvio-padrão das menos competitivas & 12,36 & 0,2984 & 0,048 & 0,1329 & \\
\hline Nível de significância do teste t & 0,00002 & 0,043 & 0,002 & 0,100 & \\
\hline r Pearson: GC $\mathrm{x}$ todas as empresas & & 0,519 & 0,889 & 0,254 & \\
\hline r Pearson: GC x empresas mais competitivas & & 0,482 & 0,716 & $-0,190$ & \\
\hline r Pearson: GC x empresas menos competitivas & & $-0,194$ & 0,821 & $-0,670$ & \\
\hline
\end{tabular}


A dispersão média das armas no campo da competição escolhido pelas empresas mais competitivas $(0,644)$ difere apenas ao nível de significância de $0,100(10 \%)$ da dispersão média das empresas menos competitivas $(0,534)$. Ou seja, não é possível afirmar com confiança superior a $90 \%$ que a dispersão média das armas no campo da competição escolhido pelas empresas mais competitivas é maior que a dispersão média das empresas menos competitivas.

Em resumo, pode-se afirmar em relação às hipóteses estatísticas do Quadro 1 que:

1. aceita-se a hipótese que há correlação muito forte entre o foco das armas no campo da competição escolhido pela empresa e o seu grau de competitividade;

2. aceita-se a hipótese que a média do foco das armas no campo da competição escolhido pelas empresas mais competitivas é maior, ao nível de significância de $5 \%$, do que a média do foco das menos competitivas;

3. aceita-se a hipótese que não há correlação entre a dispersão das armas no campo da competição escolhido pela empresa e o seu grau de competitividade; e

4. aceita-se a hipótese que a média da dispersão das armas no campo da competição escolhido pelas empresas mais competitivas não é maior, ao nível de significância de $5 \%$, do que a média da dispersão das menos competitivas.

Portanto, tanto o teste t quanto o índice de correlação permitem concluir que é o foco que explica a diferença de competitividade das empresas. Se não houvesse relação entre a correta aplicação das armas (medida pelo foco) e a competitividade da empresa, os resultados desses dois testes seriam semelhantes para o foco e para a dispersão. A dispersão serviu, então, de contraprova.

\section{Passo 4: Análise da influência da intensidade média das armas na competitividade}

A aplicação do teste $t$ (vide Tabela 4) constatou que a média da intensidade média das armas das empresas mais competitivas $(3,865)$ difere significativamente, ao nível de significância de 4,3\%, da média das menos competitivas $(3,525)$. Portanto, conclui-se, com $95,7 \%$ de confiança, que as empresas mais competitivas têm armas mais potentes que as menos competitivas.

O índice de correlação de Pearson $(r=0,519)$ indica associação muito fraca $(r<0,6)$ entre o grau de competitividade e a intensidade média das armas para o conjunto das 13 empresas. O teste de correlação linear de Pearson, mostrado na seção anterior, constatou que, numa amostra de 13 elementos, só há correlação, ao nível de significância de 5\%, para os valores do índice de correlação superiores a 0,55. Portanto, não se pode afirmar, com $95 \%$ de confiança, que há correlação entre a intensidade média das armas e o grau de competitividade das empresas. Em outras palavras, a intensidade média das armas não influencia a competitividade das empresas.

Em resumo, pode-se afirmar em relação às hipóteses a testar do Quadro 1 que:

5. aceita-se a hipótese que não há correlação, medida pelo índice de correlação de Pearson, entre a intensidade média das armas da empresa e seu grau de competitividade; e

6. aceita-se a hipótese que a média da intensidade média das armas das empresas mais competitivas é significativamente maior do que a média das menos competitivas, segundo o teste $t$ com nível de significância de $5 \%$.

4.6. Metodologia Para Ampliar A Competitividade De Uma Empresa Ou Para (Re) Formular Suas Estratégias Operacionais

Constatado nas subseções 8.3 e 8.4 que é o foco, e não a dispersão e nem a intensidade média das armas, que explica a diferença de competitividade das empresas da amostra, a regra 
para ampliar a competitividade de uma empresa torna-se óbvia: Para tornar-se mais competitiva, a empresa deve aumentar o foco por meio da implementação de medidas para aumentar a intensidade das armas relevantes. Como corolário dessa regra, a empresa deve diminuir a dispersão, reduzindo a intensidade das armas irrelevantes, o que baixará seus custos e, portanto, a tornará mais eficiente. Dessa maneira, o aumento da competitividade darse-á a custos menores.

Aumentar ou diminuir a intensidade de uma arma significa aumentar ou diminuir os investimentos e os recursos, humanos e tecnológicos, aplicados numa arma. Se um sistema de controle, por exemplo, for uma arma irrelevante, deve-se eliminá-lo ou reduzir seu escopo, liberando pessoas para trabalhar numa arma relevante.

Com essa argumentação, validam-se as hipóteses relativas aos objetivos específicos da seção 3 .

Pela metodologia do modelo CAC, a formulação das estratégias competitivas operacionais consiste simplesmente em planejar o aumento na intensidade das armas relevantes, o que aumenta o foco, e a diminuição da intensidade das armas irrelevantes, o que reduz a dispersão. Lembre-se que essas armas já foram identificadas no processo de cálculo do foco e da dispersão.

\section{DISCUSSÃO DOS RESULTADOS DA PESQUISA E CONCLUSÕES}

Este artigo mostrou a aplicação, ao estudo sobre a competitividade do setor de peças das concessionárias Chevrolet, da nova metodologia para análise e ampliação da competitividade empresarial, fundamentada no modelo CAC (Contador et al. (2006).

Analisando as estratégias competitivas de negócio, constatou-se, por meio do teste estatístico não paramétrico de Wilcoxon-Mann-Whitney, que as empresas mais competitivas e as menos competitivas adotam as mesmas estratégias de negócio, ou seja, que não há diferença significativa entre os campos da competição adotados por essas duas classes de empresas. Essa conclusão denota, em primeiro lugar, que as empresas têm percepção muito semelhante sobre os campos da competição valorizados pelos clientes e, em segundo lugar, que as estratégias de negócio não explicam a diferença no grau de competitividade das empresas. São as estratégias competitivas operacionais que explicam a diferença na competitividade das empresas. Ou seja, apenas a percepção correta dos campos da competição valorizados pelos clientes não garante competitividade às empresas - para ser mais competitiva que os concorrentes, a empresa precisa adotar adequadas estratégias competitivas operacionais.

Essa conclusão pode induzir o leitor menos familiarizado com o modelo CAC a pensar que o campo da competição não tem importância. Mas, os campos da competição são de extrema importância, tanto que eles representam a estratégia competitiva de negócio da empresa. Se a empresa não dispuser de inteligência competitiva para escolher campos valorizados pelos seus clientes (pelo menos por um nicho de clientes), ela não sobreviverá, pois não terá clientes em quantidade suficiente para sustentá-la. Por isso, tanto as empresas mais competitivas quanto as menos competitivas têm campos assemelhados. A segunda importância do campo da competição está em ser ele que orientará a escolha das armas e a definição da intensidade de cada arma, de forma a obter alto foco das armas no campo da competição escolhido.

O foco é a variável matemática que mede o critério para a empresa ser competitiva: "Para a empresa ser competitiva, não há condição mais relevante do que ter excelência apenas nas armas que lhe dão vantagem competitiva no campo escolhido para competir em cada par produto/mercado" (CONTADOR, 1995b, p. 51), ou seja, a empresa precisa dirigir 
seus esforços para as armas alinhadas ao campo da competição escolhido, o que significa ter alto foco. A variável dispersão serve como contraprova dos testes de validação desse critério, porque, como o método de cálculo do foco e da dispersão é o mesmo, se houver alto índice de correlação do grau de competitividade com o foco e baixo índice com a dispersão, fica evidente que são as armas relevantes (aquelas que contribuem para o foco, as alinhadas ao campo da competição da empresa) que dão competitividade à empresa e que as armas irrelevantes (aquelas que contribuem para a dispersão, as não alinhadas ao campo da competição da empresa) não influenciam a competitividade da empresa.

Isso foi efetivamente constatado na pesquisa de campo, pois, considerando as 13 empresas, os índices de correlação entre o grau de competitividade (medido pela variação percentual do faturamento no período de 2000 a 2005) e o foco $(0,889)$ e entre o grau de competitividade e a dispersão $(0,254$, valor que caracteriza a não existência de correlação) permitem concluir que é o foco que explica a diferença de competitividade entre as empresas, como mostrado na Tabela 4 da seção 8.3. Este resultado é bastante significativo, evidenciando que a variável foco explica, sozinha, $79 \%\left(r^{2}=0,889^{2}=0,79\right)$ da variação do faturamento da empresa.

Assim, para o setor de peças das concessionárias Chevrolet, segundo os resultados da pesquisa, se a empresa atentar para a variável foco, estará gerenciando $79 \%$ dos fatores que afetam seu faturamento. Isso de fato ocorre, pois o índice 0,889 evidencia que as empresas mais competitivas procuram alcançar alta intensidade nas armas relevantes, ou seja, as empresas mais competitivas possuem armas mais bem-alinhadas ao seu campo da competição principal do que as menos competitivas. Além disso, o teste $\mathrm{t}$ concluiu, com $99,8 \%$ de confiança, que as empresas mais competitivas têm foco médio $(0,851)$ maior que as menos competitivas $(0,745)$. Ou seja, é o foco que explica a diferença de competitividade entre as empresas.

Deve-se reforçar que, na aplicação do teste t, sempre foi tomado o cuidado de usar a distribuição t de Student, aplicável a pequenas amostras, e de verificar as duas condições necessárias para sua aplicação, conforme as razões expostas na seção 6.2 , quais sejam: $1^{a}$ ) as amostras devem ser independentes; e $2^{\mathrm{a}}$ ) a média das amostras deve ter distribuição normal.

O teste $\mathrm{t}$ concluiu, com $95,7 \%$ de confiança, que as empresas mais competitivas têm armas mais potentes que as menos competitivas. Mas, o teste do coeficiente de correlação mostrou que não há correlação entre a intensidade média das armas e o grau de competitividade, como mostrado na seção 8.4. Isso evidencia que a variável intensidade média das armas não explica a competitividade das empresas da amostra. A variável foco, sim, explica-a.

A relativamente alta intensidade média das armas de todas as empresas da amostra $(3,735)$ significa que as empresas de um modo geral procuram alcançar alto desempenho em todas as armas. Em outras palavras, atiram para todos os lados e alguns tiros acabam acertando. Mas, é importante ressaltar que não há correlação entre a intensidade média das armas e o grau de competitividade. Alta intensidade média das armas acarreta alto foco, o que é bom, mas também acarreta alta dispersão, o que significa que a empresa investiu em armas que não influenciam a sua competitividade.

Essa conclusão não chega a surpreender, pois é o que prega, há décadas, o tão disseminado movimento da Qualidade Total: a empresa precisa ter qualidade em tudo o que faz. Com esse pensamento, a empresa acaba por investir em armas irrelevantes para sua competitividade, aumentando, portanto, a dispersão. Pelo modelo CAC, a empresa deve apenas ter alta intensidade (valor igual ou maior que 4) nas armas relevantes, ou seja, nas armas que aumentam o foco, que dão competitividade à empresa. As armas irrelevantes para a 
competitividade devem ter baixa intensidade (valor 1 ou 2). Há um método para identificar as armas relevantes e as armas irrelevantes para um determinado campo da competição - a matriz de priorização das armas - descrito na seção 8.1 (para o campo preço, elas estão indicadas na Tabela 3).

Portanto, a pesquisa no setor de peças das concessionárias Chevrolet confirmou o critério do modelo CAC: "Para a empresa ser competitiva, não há condição mais relevante do que ter excelência apenas nas armas que lhe dão vantagem competitiva no campo escolhido para competir em cada par produto/mercado". Isso porque é o foco que mede a excelência nas armas que lhe dão vantagem competitiva no campo escolhido para competir.

Constatado nas seções 8.3 e 8.4 que é o foco, e não a dispersão nem a intensidade média das armas, que explica a diferença de competitividade das empresas da amostra, a regra para ampliar a competitividade de uma empresa torna-se óbvia: Para tornar-se mais competitiva, a empresa deve aumentar o foco por meio da implementação de medidas para aumentar a intensidade das armas relevantes. Como corolário dessa regra, ela deve diminuir a dispersão, reduzindo a intensidade das armas irrelevantes, o que baixará seus custos e, portanto, a tornará mais eficiente. Aumentar ou diminuir a intensidade de uma arma significa aumentar ou diminuir os investimentos e os recursos aplicados numa arma.

Pela metodologia do modelo CAC, a formulação das estratégias competitivas operacionais consiste simplesmente em planejar o aumento da intensidade das armas relevantes e a diminuição da intensidade das armas irrelevantes, armas que já foram identificadas no processo de cálculo do foco e da dispersão para o campo onde a empresa decidiu competir.

Deve-se destacar, finalmente, que o modelo CAC não utiliza indicadores como, por exemplo, o Balanced Scorecard, mas sim as relações das armas com os campos da competição. Ou seja, o modelo baseia-se na origem das vantagens competitivas, que são as armas que, por sua vez, vão afetar os indicadores de desempenho.

\section{REFERÊNCIAS BIBLIOGRÁFICAS}

ACEVEDO, C. R. e NOHARA, J. J. Monografia no curso de administração. São Paulo:Atlas,2009.

ANSOFF, Igor. Corporate strategy. New York: McGraw-Hill, 1965.

BARNEY, Jay. Strategic factor markets: expectations, luck and business strategy. Management Science, v. 32, n. 10, p. 1231-1241, 1986a.

Organizational culture: can it be a source of sustained competitive advantage? Academy of Management Review, v. 11, n. 3, p. 656-665, 1986 b.

. Firm resources and sustained competitive advantage. Journal of Management, Bloomington, v.17, n. 1, p. 99-120, Mar. 1991.

Resource-based theories of competitive advantage: a ten year retrospective on the resource-based view. Journal of Management, New York, v.27, n.6, p. 643-650, 2001.

CHANDLER, A. D. Strategy and Structure: Chapters in History of the Industrial Enterprise. Cambridge, MA: MIT Press, 1962. 
CONTADOR, J. Celso. Campos da competição. Revista de Administração (USP), São Paulo, v. 30, n. 1, p. 32-45, jan.-mar., 1995a.

. Armas da competição. Revista de Administração da USP, São Paulo, v. 30, n. 2, p. 50-64, abr.-jun., 1995 b.

Campos e armas da competição. São Paulo: Saint Paul, 2008, 608 p.

COSTA NETO, Pedro Luiz O. Estatística. São Paulo: Edgard Blücher, 1977, 264 p.

DE SORDI, J. Osvaldo; CONTADOR, J. Celso. Integração dos sistemas de informação à estratégia da organização por meio do modelo de campos e armas da competição. Revista de Administração, São Paulo, v. 40, n. 2, p. 123-135, abr. / jun.,2005.

HAMEL, Gary; PRAHALAD, C. K. Competindo pelo futuro. Rio Janeiro: Campus, 1995.

KAPLAN, R. S.; NORTON, D. P. The balanced scorecard - Measures that drive performance. Harvard Business Review. Boston, v. 70, n. 1, p.71-79, Jan./Feb. 1992.

. Putting the balanced scorecard to work. Harvard Business Review. Boston, v. 71, n. 5, p. 134-142, Sep./Oct. 1993.

Using the balanced scorecard as a strategic management system. Harvard Business Review. Boston, v. 74, n. 1, p.75-85, Jan./Feb. 1996.

A estratégia em ação. Rio de Janeiro: Campus, 1997.

KROGH, G.; ROSS, J. A perspective on knowledge, competence and strategy. Personal Review, Farnborough, v.24, n.3, p. 56-76, June 1995.

LEARNED, E. P.; CHRISTENSEN, C.R.; ANDREWS, K. R.; GULTH, W. D. Business Policy: Test and Cases. Homewood: Irwin, 1965.

MENDENHALL, W. Introduction to probability and statistics. Belmont: Wadsworth, 1963.

PETERAF, M.A. The cornerstones of competitive advantage: a resource-based view. Strategic Management Journal, West Lafayette, Indiana, USA Chichester, v.14, n.3, p. 17988, Mar. 1993.

POPPER, Karl. The logic of scientific discovery. New York, Harper \& Row, 1968.

PORTER, Michael E. How competitive forces shape strategy. Harvard Business Review, p. 137-145, Nov./Dec., 1979.

Competitive Strategy. New York: Free Press, 1980.

Competitive Advantage. New York: Free Press, 1985.

PRAHALAD, C. K.; HAMEL, G. The core competence of the corporation. Boston: Harvard Business Review, v. 68, n. 3, 1990. 
Strategy as a field of study: why search for a new paradigm? Strategic Management Journal, n.15, p. 5-16, 1994.

SELZNICK, P. Leadership in Administration: A Sociological Interpretations. Evanston: Row, Peterson, 1957.

WERNERFELT, B. A resource-based view of the firm. Strategic Management Journal, n. 5, p. 171-180, 1984. 